\title{
Outbreak of unusual Salmonella enterica serovar Typhimurium monophasic variant 1,4 [5],12:i:-, Italy, June 2013 to September 2014
}

F Cito ${ }^{1}$, F Baldinelli ${ }^{1}$, P Calistri ${ }^{1}$, E Di Giannatale ${ }^{1}$, G Scavia ${ }^{2}$, M Orsini ${ }^{1}$, S lannetti ${ }^{1}$, L Sacchini ${ }^{1}$, I Mangone $^{1}$, L Candeloro ${ }^{1}$,

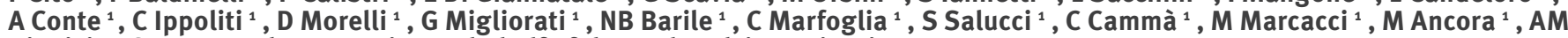
Dionisi $^{2}$, S OwCzartek ${ }^{2}$, I Luzzi ${ }^{2}$, on behalf of the outbreak investigation group 9

1. Istituto Zooprofilattico Sperimentale dell'Abruzzo e del Molise, Teramo, Italy

2. Istituto Superiore di Sanità, Rome, Italy

3. Pediatric Unit, San Salvatore Hospital of L'Aquila, Italy

4. Analytical Laboratory, San Salvatore Hospital of L’Aquila, Italy

5. Veterinary and Food Hygiene Service, Abruzzo Region, L’Aquila, Italy

6. Food Hygiene and Nutrition Service, Abruzzo Region, L'Aquila, Italy

7. Public Health Service, Abruzzo Region, L’Aquila, Italy

8. Regional Environmental Protection Agency, Abruzzo Region, L’Aquila, Italy

9. The members of the group are listed at the end of the article

Correspondence: Francesca Cito (f.cito@izs.it)

Citation style for this article:

Cito F, Baldinelli F, Calistri P, Di Giannatale E, Scavia G, Orsini M, Iannetti S, Sacchini L, Mangone I, Candeloro L, Conte A, Ippoliti C, Morelli D, Migliorati G, Barile NB, Marfoglia C, Salucci S, Cammà C, Marcacci M, Ancora M, Dionisi AM, Owczartek S, Luzzi I, on behalf of the outbreak investigation group. Outbreak of unusual Salmonella enterica serovar Typhimurium monophasic variant 1,4 [5],12:i:-, Italy, June 2013 to September 2014. Euro Surveill. 2016;21(15):pii=30194. DOI: http:// dx.doi.org/10.2807/1560-7917.ES.2016.21.15.30194

Article submitted on 15 April 2015 / accepted on 14 April 2016 / published on 14 April 2016

Monophasic variant of Salmonella enterica subspecies enterica serovar Typhimurium (monophasic S. Typhimurium), with antigenic structure 1,4,[5],12:i:-, appears to be of increasing importance in Europe. In Italy, monophasic S. Typhimurium represented the third most frequent Salmonella serovar isolated from human cases between 2004 and 2008. From June 2013 to October 2014, a total of 206 human cases of salmonellosis were identified in Abruzzo region (Central Italy). Obtained clinical isolates characterised showed S. Typhimurium $1,4,[5], 12: \mathrm{i}:-$ with sole resistance to nalidixic acid, which had never been observed in Italy in monophasic S. Typhimurium, neither in humans nor in animals or foods. Epidemiological, microbiological and environmental investigations were conducted to try to identify the outbreak source. Cases were interviewed using a standardised questionnaire and microbiological tests were performed on human as well as environmental samples, including samples from fruit and vegetables, pigs, and surface water. Investigation results did not identify the final vehicle of human infection, although a link between the human cases and the contamination of irrigation water channels was suggested.

\section{Introduction}

Monophasic variant of Salmonella enterica subspecies enterica serovar Typhimurium (monophasic $S$. Typhimurium), with antigenic structure 1,4 [5],12:i:-, is considered an emergent pathogen in many European countries [1]. It accounted for $4.6 \%, 7.2 \%$ and $8.6 \%$ of total cases of salmonellosis reported to the European Surveillance System (TESSy) in 2011, 2012 and 2013 respectively [2], and ranked third among the Salmonella serovars identified in humans in the European Union (EU) during this period.

Human infection is usually acquired through the consumption of contaminated food and several food-borne outbreaks caused by this serovar have been reported in Canada, Europe and the United States (US) [1-3]. Fresh beef and pork account for the major sources of infection, but dried sausages and frozen chicken pies have also been implicated in food-borne outbreaks, as well as vegetables and juices. The majority of monophasic $S$. Typhimurium isolates detected in live animals originates from pigs [3]. Human outbreaks potentially related to environmental sources, including water, have been also observed [4-8].

In Italy, the laboratory-based surveillance network for enteric pathogens EnterNet Italia [9] provides information on the microbiological characteristics of Salmonella spp. strains isolated from humans. The data are gathered through a network of regional reference laboratories which characterise the strains isolated from peripheral diagnostic laboratories. The EnterNet Italia network is coordinated by the National Reference Laboratory for Salmonella infection in humans of the Istituto Superiore di Sanità (ISS). 
Number of confirmed, probable and possible monophasic Salmonella Typhimurium outbreak cases based on symptom onset week $^{\mathrm{a}}$, Italy, 2 June 2013-27 September $2014(\mathrm{n}=204)^{\mathrm{b}}$

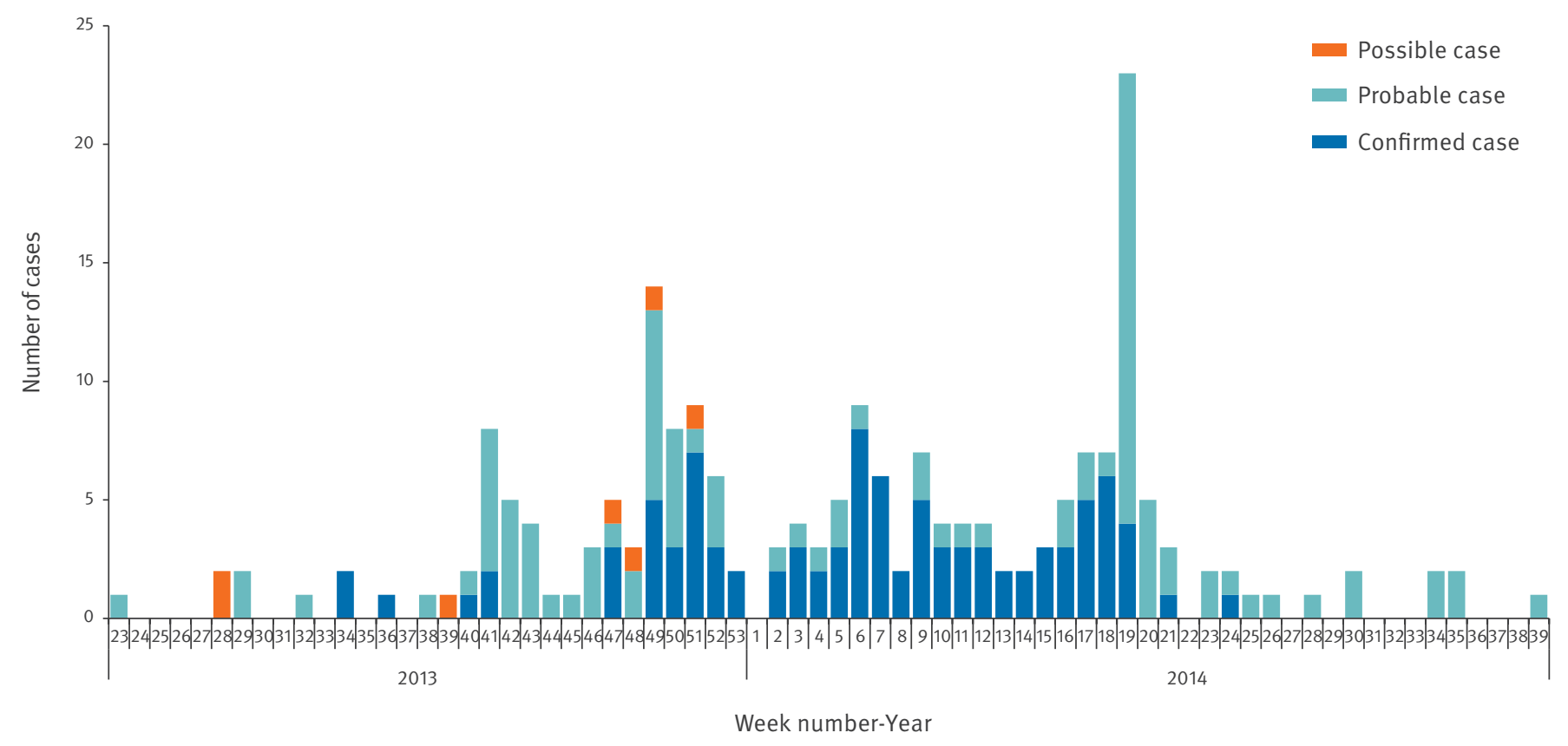

${ }^{a}$ For 57 cases symptom onset date was not known and specimen date was used.

${ }^{b}$ Although a total of 206 cases were part of the outbreak, only 204 are depicted in this figure because for two confirmed cases the onset day and the specimen date were missing information.

According to EnterNet data, monophasic S. Typhimurium represented the third most frequent Salmonella serovar isolated from clinical samples in the country between 2004 and 2008 [10], ranking second in 2009 [11]. It accounted for 2.95 isolates per 100,000 population/ year between 1980 and 2011, with particularly high isolation rates in children aged one to five years [12]. Strains characterised by resistance to ampicillin, streptomycin, sulfafurazole, and tetracycline (ASSUT) (with or without additional resistances) represented $75 \%$ of all the monophasic $S$. Typhimurium isolates from either 2008 or 2009 . Forty-eight per cent of strains belonged to $\mathrm{DT}_{193}$ and $13 \%$ to U302. The most common pulsed field gel electrophoresis (PFGE) profiles were STMXB 00131 (47\%) and STMXB 0079 (37\%) [3].

In October 2013 a significant increase of human cases of salmonellosis in L'Aquila province (Abruzzo region, Central Italy) was reported to EnterNet Italia. In the period between June and October 2013 only, ca 30 salmonellosis cases, corresponding to 9.9 cases per 100,000 population [13], were observed in the L'Aquila province, clearly excessing levels of previous recent years. For example, between 2005 and 2009, the average number of salmonellosis cases notified in the province was equal to nine per year, with a maximum value of 30 annual cases in 2005 [14]. The vast majority of cases observed in L'Aquila province during 2013 and 2014 was due to monophasic S. Typhimurium. Isolates from patients' stool samples were indistinguishable by traditional typing methods, such as phage type, PFGE and multilocus-variable number tandem repeat Analysis (MLVA) and were solely resistant to nalidixic acid, which had never been observed in Italy in monophasic S. Typhimurium neither in humans nor in animals or foods [15]. According to TESSy, monophasic $S$. Typhimurium with this peculiar antimicrobial profile had also rarely been reported in the EU.

Here we present the results of the epidemiological, environmental and molecular investigations carried out in the Abruzzo region in 2013-2014. The aims of these investigations were to gather relevant information on exposures and to identify the potential sources of infection so as to allow adequate control measures.

\section{Methods}

Case ascertainment and case definition

Following the observation of the significant increase of human cases of salmonellosis in L'Aquila province (Abruzzo region, Central Italy), an alert was sent to all public health services of Abruzzo region in October 2013. Prospective and retrospective active finding of cases was conducted for the period from January 2013 to October 2014, involving hospitals in Abruzzo as well as microbiological laboratories in the whole Italy through the EnterNet Italia surveillance network. 


\section{FIGURE 2}

Geographical distribution of outbreak cases $(n=115)^{\text {a }}$ and of surface and sewage water samples $(\mathrm{n}=21)$ with a monophasic Salmonella Typhimurium outbreak strain isolate, L’Aquila province, Italy, April-October 2014

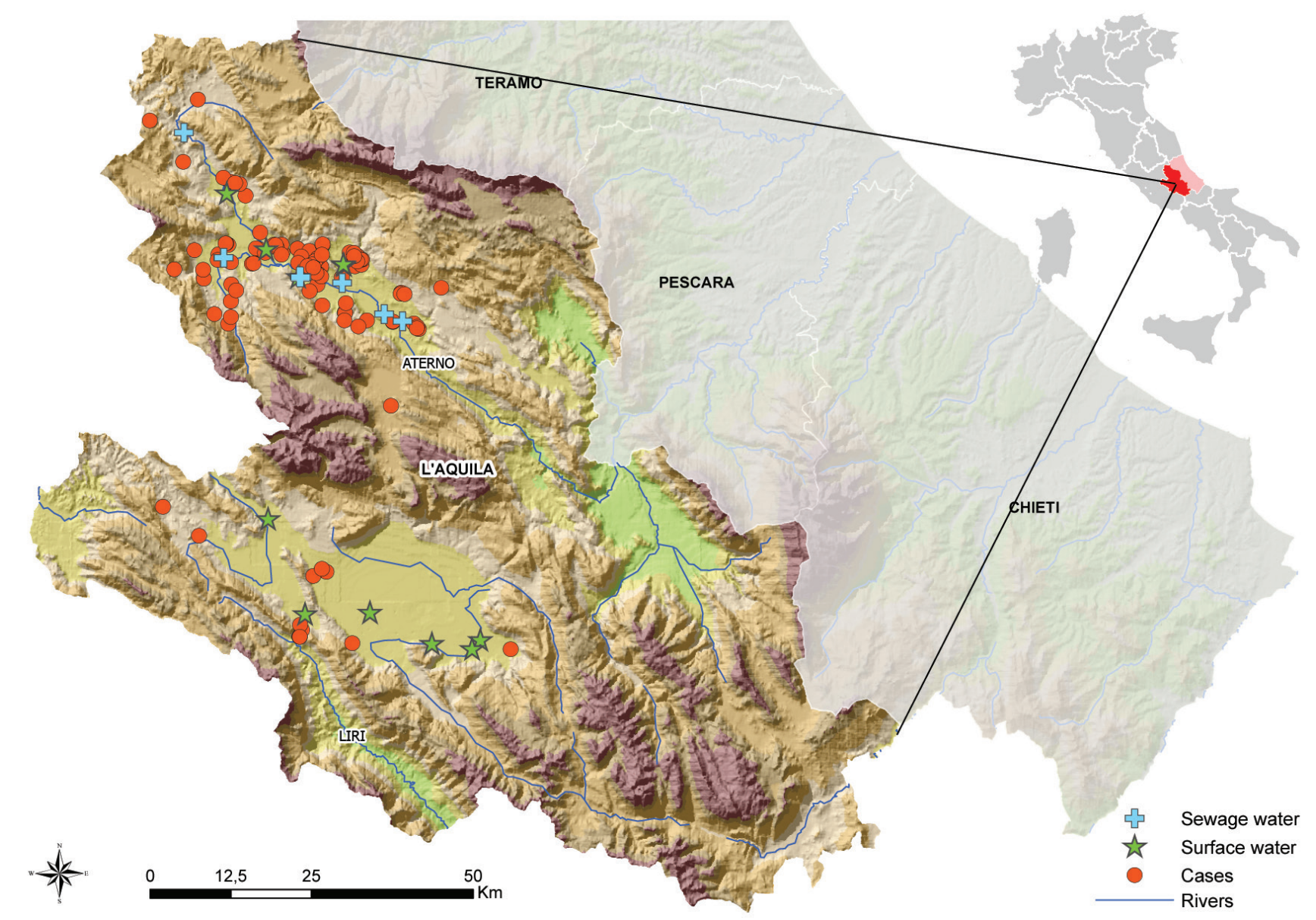

${ }^{a}$ Although there were a total of 179 outbreak cases in the Abruzzo region, only 115 are depicted in this figure because for 64 cases the residential address was missing information.

The outbreak strain was defined as: 'monophasic $S$. Typhimurium resistant to nalidixic acid, with a PFGE profile equal to the reference type XBAI.0027 and MLVA 3-14-11-NA-211 encoded by the molecular surveillance service (MSS) of the European Centre for Disease Prevention and Control (ECDC)'.

Definitions of possible, probable and confirmed cases were established on the basis of phenotypic and genotypic characteristics of the Salmonella isolates, and the existence of a possible epidemiological link with Abruzzo region (people living in Abruzzo or reporting to have travelled to Abruzzo in the seven day-period before the disease onset). A confirmed case was a patient epidemiologically linked to Abruzzo, who was laboratory confirmed with the outbreak strain from January 2013 onwards. A probable case was a patient epidemiologically linked to Abruzzo, who was laboratory confirmed with Salmonella group B from June 2013 onwards. A possible case was a patient with gastroenteritis epidemiologically linked to Abruzzo from June
2013 onwards, but who was not laboratory confirmed with Salmonella.

An international alert was also launched through the European Epidemic Intelligence Information System (EPIS) in April 2014.

\section{Epidemiological investigations}

From October 2013, cases were requested to respond to a standardised questionnaire. This was administered by a face to face interview of either the patients or, if they were younger than 18 years-old, their parents. Until the end of March 2014 the questionnaire was generic and included only information on demographic data and presence of clinical symptoms. Starting from April 2014, a more elaborate version was used to also collect information on the occurrence, duration and severity of clinical symptoms, healthcare seeking behaviours, and exposures possibly presenting a risk for Salmonella infection in the seven days before symptoms onset. These included exposure to possible animal reservoirs, contact with people with gastrointestinal illness, as 
Geographical distribution and microbiological testing results of surface and sewage water samples in the L'Aquila province, Italy, April-October $2014(\mathrm{n}=302)$

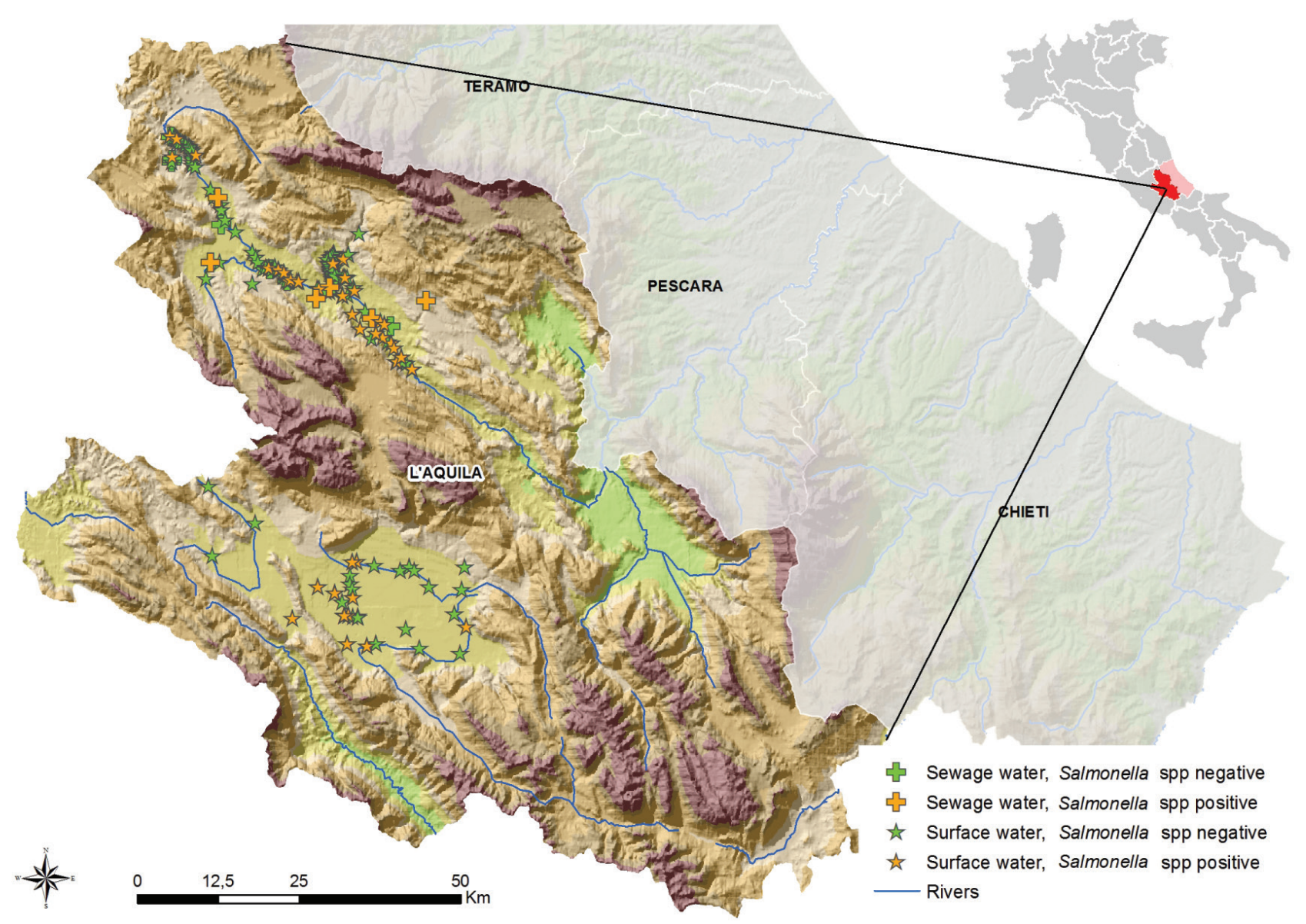

well as travel, details on food and beverages consumed including their purchase places, and the consumption of meals out of home. Cases were also asked about the consumption of local handmade food products of animal and vegetable origins.

The implementation of a case-control study was originally considered but could not be realised due several difficulties which are further discussed.

Data from the questionnaires were entered into a database using Epi Info 7 (Centers for Disease Control and Prevention, Atlanta, United States (US)). Data management and analysis were performed using Stata 12 (Stata Corporation, Texas, US). Data derived from the 2011 demographic census performed by the Italian National Institute of Statistics (ISTAT) were used to calculate the attack rates [16]. The possible existence of a relationship between the age of cases and both the duration of clinical symptoms and disease severity was assessed by the calculation of Kendall's rank correlation coefficient.

\section{Environmental investigation}

Given the temporal and spatial extension of the outbreak, a possible implication of environmental sources was suspected. Accordingly, the regional health authorities established a microbiological monitoring plan in April 2014. This included sampling of all commercial pig herds of L'Aquila province (faecal, dust, drinking water and feed samples were taken in each herd), and the examination of ileocaecal lymph nodes taken from swine at slaughterhouses to assess the status of Salmonella infection in pigs bred and slaughtered in the province. In addition, locally produced fruit and vegetables, mainly fresh vegetables grown in open fields and intended to be consumed raw, were directly collected in a subset of producing farms. These farms were selected on the basis of the results of surface water sampling, which was performed as further described. In each cultivated field at least eight samples of fruit and vegetables, with the minimum weight of $2 \mathrm{~kg}$ and chosen to be representative of the whole cultivated surface, were taken. Overall, 23 pig herds, 11 swine slaughterhouses and 17 fruit and vegetableproducing farms in L'Aquila province were investigated.

The monitoring plan also concerned surface water. Channels used for irrigation (including at farm sites) were sampled as well as surface water from three main catchment basins of the Tevere, Liri-Garigliano and Aterno rivers and their tributaries. Nine sewage water 
Maximum likelihood relationship of monophasic Salmonella Typhimurium whole genome sequences, obtained from environmental water and clinical samples during an outbreak of monophasic Salmonella Typhimurium, L'Aquila province, Italy, April-October 2014

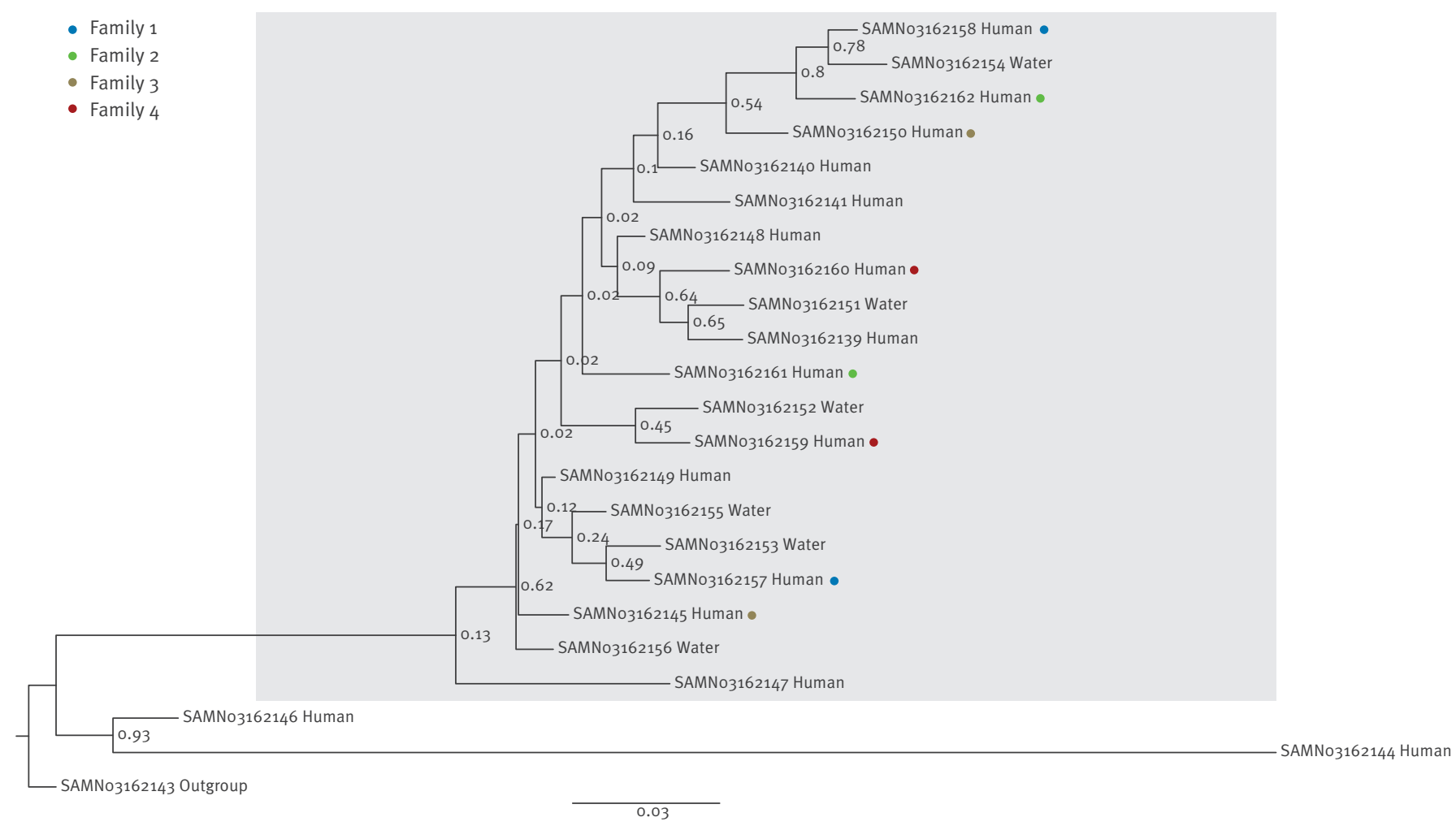

Bootstrap values are indicated at the tree nodes. The scale bar denotes the estimated number of nt substitutions per site.

treatment plants were additionally subjected to microbiological controls on fluids entering and leaving the plants. The sampling programme was performed until the end of October 2014 .

Daily data on rainfall covering a period from September 2013 to June 2014 [17] were obtained from the Centre of Excellence for the Remote Sensing and Forecast of Severe Weather (CETEMPS) of L'Aquila University and a preliminary analysis was conducted to assess the possible association between rainfalls and the occurrence of salmonellosis cases, using the Pearson's correlation coefficient. The correlation was evaluated through a cross-correlation approach by using two different time lags: the time shift between rain and cases detection and a time window used to average the quantities of rain along a period of time before the occurrence of cases. Data were aggregated using five days interval since this was considered the best temporal aggregation to summarise and analyse data on rainfall and on the occurrence of salmonellosis case. Only cases occurring in the L'Aquila municipality and in the neighbouring municipalities were included in the analysis, since available data on rainfall referred to that area. The analysis was performed using the $R$ free package [18].

\section{Characterisation of strains}

Biochemical identification of isolates was conducted using the automated Vitek 2 system (Biomerieux, Marcy l'Etoile, France). The isolates were serotyped with commercial antisera (Statens Serum Institut, Copenhagen, Denmark) according to the Kauffmann-White scheme by slide agglutination. After having identified the somatic antigen and the phase- 1 flagellar antigen, if the second one was negative, the phase inversion method was used to allow the expression of the second flagellar phase. Strains were assigned to Salmonella serovar Typhimurium monophasic variant 1,4 [5],12:i:- on the basis of a multiplex polymerase chain reaction (PCR) [19]. Antibiotic susceptibility of isolates was evaluated by disk diffusion method [20]. Phage typing was performed using $S$. Typhimurium phages according to the method described by Anderson et al. [21]. Strains were typed by PFGE and MLVA according to the ECDC Laboratory standard operating procedures [22,23].

The genomes of 20 respective strains matching the outbreak strain definition and isolated from human $(n=14)$ and environment samples ( $n=6$; five from sewage plants and one from surface water) were fully sequenced. They were chosen on the basis of geographical location, timeline isolation and biochemical properties. Moreover most of the strains chosen to be 
Results of the environmental investigations on samples taken in pig herds, farms, slaughterhouses, sewage treatment plants and from surface waters in L'Aquila province, Italy, April-October 2014

\begin{tabular}{|c|c|c|c|}
\hline Sampling place & Sample type & Number & $\begin{array}{l}\text { Samples positive for the outbreak strain of monophasic } \\
\text { Salmonella Typhimurium }\end{array}$ \\
\hline \multirow{4}{*}{ Pig herds } & Dust & 26 & 0 \\
\hline & Faeces & 41 & 0 \\
\hline & Feed & 34 & 0 \\
\hline & Drinking water & 22 & 0 \\
\hline \multirow{5}{*}{ Farms } & Bulb vegetables & 9 & 0 \\
\hline & Root vegetables & 13 & 0 \\
\hline & Leaf vegetables & 9 & 0 \\
\hline & Fruits & 6 & 0 \\
\hline & Irrigation water & 4 & 1 \\
\hline Slaughterhouses & Swine ileocaecal lymph nodes & 32 & 0 \\
\hline Sewage treatment plants & Effluent water & 111 & 9 \\
\hline Rivers and water channels & Surface water & 191 & 11 \\
\hline Total & - & 498 & 21 \\
\hline
\end{tabular}

fully sequenced were isolated from cases belonging to the same families, whereby cases belonging to a family lived in the same household. Three additional isolates, two unrelated outbreak monophasic $S$. Typhimurium isolates (differing from outbreak strain for antimicrobial resistance patterns) and a further strain isolated five years prior, were also sequenced and added as controls and outgroup respectively. Whole genome sequencing was performed by a Personal Genome Machine (PGM) Ion torrent platform. After quality trimming, retained reads were in the 40 to $350 \mathrm{nt}$ length range, exhibiting an average phred score of 30 and providing an estimated coverage spanning from $18 \mathrm{x}$ to $45 \mathrm{x}$ for the selected isolates. Trimmed reads were submitted to the Sequence Read Archive (SRA) repository [24] under the Bioproject accession number SRP049581 and were used to build a single nucleotide polymorphism (SNP) reference-based matrix using the US Food and Drug Administration (FDA) SNP-pipeline programme [25]. The phylogenetic tree was built using the TamuraNei model in molecular evolutionary genetics analysis (MEGA)6 [26]. Confidence of branch points was estimated by Fast bootstrap analysis with 500 replicates.

\section{Results}

\section{Outbreak description}

A total of 206 cases (98 confirmed, 101 probable, 7 possible) were identified in Italy between June 2013 and September 2014 (Figure 1). No cases possibly linked to this outbreak were reported from the 14 countries (including the US) reacting to the EPIS alert.

Of the 206 cases, the place of residence was unknown for 19. Among those with available information, only eight cases were detected outside the Abruzzo region. In this region with a total of 179 cases, most $(n=146)$ were reported from the province of L'Aquila. The attack rate was 14 cases per 100,000 inhabitants in Abruzzo region (95\% confidence interval $(\mathrm{Cl}): 12-16)$, and 49 cases per 100,000 inhabitants in L'Aquila province (95\% Cl: 41-58). Information on patient's age was collected for 192 cases and the median value was 4 years (range: 0-91 years). The age of cases significantly differed (Fisher's test $p<0.01$ ) from that of the Abruzzo population, taken as 'control' population, and the greatest number of cases ( $n=98 ; 51 \%$ ) occurred in patients aged between one and four years (Pearson's chi-squared: 1,248; $p<0.01)$. No significant difference was observed by sex ( $53 \%$ males and $47 \%$ females).

Data on clinical signs were complete for 90 patients and the mean duration of illness was seven days (range: 1-30 days). Diarrhoea was the most important symptom (89/90; 99\%), followed by abdominal pain (57/85; $67 \%)$, weakness (22/39; 56\%), bloody diarrhoea (19/46; $41 \%)$, vomiting $(32 / 86 ; 37 \%)$, fever defined as $>37.5^{\circ} \mathrm{C}$ $(28 / 92 ; 30 \%)$, nausea $(13 / 77 ; 17 \%)$, and diffuse pain (4/35; 11\%). Among symptomatic cases, 46 (51\%) were hospitalised. The median age of hospitalised patients was four years (range: 1-91 years). No significant correlation was observed between the age of cases and the duration of the illness (Kendall's coefficient $=0.03$ ) or its severity (Kendall's coefficient $=0.05$ ). A man aged $>70$ years died following the $S$. Typhimurium infection.

\section{Epidemiological investigation}

Of a total 112 cases approached for interviews, 106 took part in the questionnaires, corresponding to a participation rate of $95 \%$. Of these, 51 cases answered to the first generic questionnaire (48\%) and 55 to the following more elaborate version ( $51 \%)$. Not all questions on clinical signs, travel history, animal or ill person 
exposure, and on the food and beverage consumption were properly answered by all interviewed cases, thus the number of respondents for each question must be taken into account.

During the week before disease onset, eight of 49 respondents (16\%) reported to have travelled. These eight cases resided in L'Aquila and had travelled outside the Abruzzo region (however, no cases travelled to the same place) and 24 of 95 (25\%) respondents reported contacts with an individual presenting gastrointestinal illness. Contacts with pets were reported by 31 of 90 cases $(34 \%)$.

In the week prior to the onset of the disease, 38 of 49 cases had consumed food outside their home: in school canteens (20/41), in restaurants (10/49), in bars (13/44), in fast foods (7/45), or in other places (8/23). As far as school canteens are concerned, the investigation was extended to verify possible common food suppliers and no common places or epidemiological links were identified.

The investigation on food eating habits did not reveal the consumption of any particular food considered at risk for Salmonella infection, apart from eggs and vegetables. Most of the cases reported drinking tap or bottled water, respectively 41/66 (62\%) and 56/76 (74\%).

\section{Environmental investigation}

All samples taken among the pig herds $(n=123)$, the fruit and vegetables produced by farms $(n=37)$, and in the slaughterhouses $(n=32)$ from April to October 2014 tested negative for Salmonella (Table ). Monophasic S. Typhimurium isolates, fitting the definition of outbreak strain, were detected in 11 of 191 samples of surface water, in one of four samples of irrigation water taken on farms, and in nine of 111 samples of sewage treatment plants taken in several geographical locations of L'Aquila province (Table).

The positive sample of irrigation water was taken from irrigation pipelines with water from the Vera river, which is tributary of the Aterno river, and from which surface water samples also tested positive. The samples of fruit and/or vegetables taken from the fields irrigated with the contaminated water were negative for Salmonella. Monophasic S. Typhimurium outbreak strain was detected in five sewage treatment plants localised on the Aterno river and in one sewage treatment plant localised on the Raio stream flowing into Aterno river (Figure 2). The geographical location of 21 water samples testing positive for monophasic $S$. Typhimurium with the same characteristics as the outbreak strain is shown in Figure 2.

In addition, three further surface water and five sewage samples resulted positive for monophasic $S$. Typhimurium, but showing different phenotypic characteristics than the outbreak strain, while another 50 samples (34 of surface waters and 16 of sewage) were positive for other Salmonella serovars. The geographical locations of 302 sewage and surface water samples, which were microbiologically analysed as well as their testing results are reported in Figure 3.

The analyses performed to explore the possible correlation between rainfalls and the occurrence of salmonellosis cases gave a significant value of the Pearson's coefficient (0.47) when an increase of the average value of rainfall over a 10 day period was considered and for a time shift between rain and cases detection of 20 days.

\section{Characterisation of strains}

Phylogenetic relationships among the selected isolates were investigated using the SNP matrix obtained from the whole genome sequencing. The single maximum parsimonious (MP) and maximum likelihood (ML) analyses resulted in a single tree with similar topology (Figure 4). The two strains not matching the definition of outbreak strain, clustered as a separate clade with high bootstrap support, and one of them differed from the antigenic profile (SAMN03162144), while the other exhibited a completely different antimicrobial resistance profile (SAMN03162146). In contrast, outbreakrelated isolates were grouped in a well-separated clade from the other strains. However, genetic relationships among isolates (both from patients and water samples) inside the outbreak clade were supported by very low bootstrap values (range: 13-80\%). Subclades with higher bootstrap values include both water and clinical-related strains.

\section{Discussion}

In the outbreak described here, cases were solely identified in Abruzzo region and occurred continuously and uninterruptedly from June 2013 to September 2014. The outbreak strain was repeatedly isolated in sewage treatment plants and surface water, including water used for irrigation in the region. A cross-correlation analysis between rain episodes and human cases moreover showed that an increased level of rainfalls (averaged over a 10 days period) preceded the onset of salmonellosis cases by ca 20 days. Whole genome sequencing phylogenetic analysis, albeit not robust, also indicated some relationships between clinical and water strains. To gain more information on whether outbreak strains could be of clonal origin, the phylogenetic distances among the outbreak isolates would need to be carefully evaluated taking into account the relative long period of time during which the human cases occurred and the subsequent higher probability of Salmonella population differentiation and heterogeneity.

Taken together, the results are in line with the hypothesis of a waterborne mechanism for the outbreak, and might suggest a possible relationship between heavy precipitations and the presence of Salmonella in surface waters, maybe via the flooding of sewage treatment plants, subsequently leading to contamination of irrigation waters. That floods, as result of intensive 
precipitation events, bring pathogens from sewage water to surface water is a known phenomenon: heavy rainfalls in a relatively short time can cause sewer overflows to surface water and/or soil, thus increasing the risk of contaminating irrigation waters [27]. Here, the contamination of surface and irrigation waters by the outbreak strain could also have been due to problems with the treatment plants or to persisting damage inflicted to water pipelines of the sanitary sewer system of the city of L'Aquila and surrounding villages by the devastating earthquake in 2009.

In the environmental investigation, the apparent absence of the outbreak strain in pigs reared in the Abruzzo region and the negative microbiological results in fruits and vegetables, may suggest the existence of yet undetected infection reservoirs, such as wild animals. Nevertheless, given the time elapsed between the possible occurrence of an environmental contamination and the collection of samples, the results cannot definitely rule out pigs or vegetables as sources of infection. Fruits and vegetables may be generally colonised by a wide variety of microorganisms and Salmonella is usually associated to fresh produce [28]. The occurrence of Salmonella in whole and freshcut leafy greens has been reported [1] and outbreaks due to $S$. Typhimurium, which may survive for extended time periods in manure and manure-amended soils [29], have been associated with the consumption of fresh lettuce [30]. Rainfalls have also been proven to play a role in Salmonella dispersal and contamination of tomato plants in the field, especially during concentrated and relatively intense rain events and when plastic mulch was used [6].

Aside from contamination via animal manure for fertilization purposes, it is also well known that vegetables can become contaminated with pathogens by irrigation water [31]. In the US this was confirmed in repeated incidents: a multistate outbreak of Salmonella Newport infection associated with eating tomatoes in 2002 and 2005 [5], an E. coli 0157:H7 outbreak associated with shredded lettuce in 2006 [32] and the outbreak caused by Salmonella Saintpaul, which was found in irrigation water and in Serrano peppers [33].

A ban of using surface water to irrigate produce and other crop due to the presence of Salmonella spp. in some areas of L'Aquila province was already in force since September 2013, before the peak of the outbreak. Unfortunately the ban was just applied to a limited area of L'Aquila province. Only starting from June 2014 did the local health authorities ban the use of surface water for crop irrigation on a larger area [34-36]. Sanitization interventions were subsequently performed in water cleaning plants and no more human cases were observed after September 2014. The role of banning the use of surface waters for irrigation in the cessation of the outbreak can nevertheless not be ascertained and the possibility of multiple transmission routes from the environment to humans, involving food-vehicles, cannot be excluded.

The observed higher incidence in patients aged between one and four years-old is not surprising in Salmonella infections, given the increased vulnerability of children and the elderly to this infection. On the other hand, this finding could suggest the implication of food vehicles normally consumed also by children or the contamination of drinking water.

A case-control study would have added more significant information on the possible source of this outbreak. Although originally considered and planned, this study proved impossible. Indeed, the uncertainties on the times of first exposures due to interventions occurring late in the outbreak progress made it difficult to find suitable controls. In addition, the realisation of such a study was hampered by the extended geographical area involved.

During the period of the outbreak there was also an increase of cases of Salmonella infections due to Salmonella strains different from the outbreak strain. Since laboratory diagnosis concerned solely Salmonella spp. no other pathogen was investigated. The characterization of all pathogens responsible for cases of gastroenteritis might have added more information on the possible source of this outbreak and possibly further supported the hypothesis of a waterborne mechanism.

The delays between generating hypotheses on the contamination routes and implementing the sampling programme and interviews of cases could also have affected the identification of a food vehicle. This confirms once again the importance of having an effective epidemiological surveillance system in place, to early identify all possible suspected clusters of infection and to quickly mobilise the human and diagnostic resources for a rapid identification of sources and vehicles of infection.

Outbreak investigation group

Gabriella Bottone ${ }^{3}$, Gianfranco Bruno4 ${ }^{4}$ Francesca De Paulis5, Maria Di Giampalma ${ }^{5}$, Maria Di Luzio ${ }^{6}$, Maria Graziani', Chiara Tuccella ${ }^{7}$, Giovannella Vespa ${ }^{8}$.

\section{Acknowledgement}

The authors acknowledge the contribution of the Abruzzo Regional Veterinary Service and of all the personnel of the Istituto Zooprofilattico Abruzzo and Molise. This study has been partially funded by the 2010 targeted research project of Italian Ministry of Health RF-2010-2310899 titled 'Campylobacter, L. monocytogenes and Verocytotoxin producing E. coli (VTEC) in Italy: a molecular epidemiology approach to identify sources of infection and risk factors for human exposure' and by a grant of the Italian Ministry of Health, Centro Nazionale per la Prevenzione ed il Controllo delle Malattie (CCM) entitled 'Sorveglianza delle malattie trasmesse da alimenti e acqua (EnterNet): adeguamento del sistema italiano al quadro normativo europeo' 1616-2014. 
Conflict of interest

None declared.

\section{Authors' contributions}

FC: coordination of outbreak investigation, designed the questionnaire, data analysis, drafted the article. FB: designed the questionnaire, fulfilled the databases, data analysis, drafted the article. PC: coordination of outbreak investigation, drafted the article. EDG, LS, AMD, SO, NBB, CM, SS: laboratory typing on human and environmental samples. GS: coordination of outbreak investigation, drafted the article. MO: phylogenetic tree building, drafted the article. SI: Contributed data into the databases. IM: sequencing data analysis. LC: data analysis. AC: GIS outbreak coordination data analysis. CI: GIS outbreak coordination, database management. DM, GM: coordination of outbreak investigation. CC, MM, MA: laboratory sequencing. IL: coordination of outbreak investigation, laboratory reporting of cases, drafted the article. GB, GB: laboratory work on human sample. FDP, MDG, MDL, GV: done the environmental investigation. MG, $\mathrm{CT}$ : done the case interviews. All the authors: reviewed and approved the article.

\section{References}

1. European Food Safety Authority, European Centre for Disease Prevention and Control,. The European Union Summary Report on Trends and Sources of Zoonoses, Zoonotic Agents and Food-borne Outbreaks in 2012.EFSA Journal.2014;12(2):3547.

2. European Food Safety Authority, European Centre for Disease Prevention and Control,. The European Union Summary Report on Trends and Sources of Zoonoses, Zoonotic Agents and Food-borne Outbreaks in 2013.EFSA Journal.2015;13(1):3991.

3. European Food Safety Authority Panel on Biological Hazards (BIOHAZ),. Scientific opinion on monitoring and assessment of the public health risk of "Salmonella Typhimurium-like" strains.EFSA Journal.2010;8:1826.

4. Angelo KM, Chu A, Anand M, Nguyen TA, Bottichio L, Wise M, et al. Outbreak of Salmonella Newport infections linked to cucumbers--United States, 2014. MMWR Morb Mortal Wkly Rep. 2015;64(6):144-7.PMID: 25695319

5. Greene SK, Daly ER, Talbot EA, Demma LJ, Holzbauer S, Patel NJ, et al. Recurrent multistate outbreak of Salmonella Newport associated with tomatoes from contaminated fields, 2005. Epidemiol Infect. 2008;136(2):157-65. DOI: 10.1017/ So95026880700859X PMID: 17475091

6. Cevallos-Cevallos JM, Danyluk MD, Gu G, Vallad GE, van Bruggen AH. Dispersal of Salmonella Typhimurium by rain splash onto tomato plants.J Food Prot. 2012;75(3):472-9. DOI: 10.4315/0362-028X.JFP-11-399 PMID: 22410220

7. Kozlica J, Claudet AL, Solomon D, Dunn JR, Carpenter LR. Waterborne outbreak of Salmonella I 4,[5],12:i:-.Foodborne Pathog Dis. 2010;7(11):1431-3. DOI: 10.1089/fpd.2010.0556 PMID: 20617936

8. Ailes E, Budge P, Shankar M, Collier S, Brinton W, Cronquist $A$, et al. Economic and health impacts associated with a Salmonella Typhimurium drinking water outbreak-Alamosa, CO, 2008. PLoS One. 2013;8(3):e57439. DOI: 10.1371/journal. pone.0057439 PMID: 23526942

9. Surveillance program EnterNet Italia. Available from: http:// www.iss.it/ente/

10. Dionisi AM, Graziani C, Lucarelli C, Filetici E, Villa L, Owczarek $\mathrm{S}$, et al. Molecular characterization of multidrug-resistant strains of Salmonella enterica serotype Typhimurium and Monophasic variant (S. 4,[5],12:i:-) isolated from human infections in Italy. Foodborne Pathog Dis. 2009;6(6):711-7. DOI: 10.1089/fpd.2008.0240 PMID: 19580448

11. Istituto Superiore di Sanità (ISS). ENTERNET Salmonella. Sorveglianza delle infezioni da Salmonella. Dati Storici dal 2007 al 2009. Rome: ISS; 2010. Italian. Available from: http://www.iss.it/binary/salm/cont/4f_Dati_ SALMONELLA_2007_2009.pdf

12. Graziani C, Mughini-Gras L, Owczarek S, Dionisi A, Luzz I, Busani L. Distribution of Salmonella enterica isolates from human cases in Italy, 1980 to 2011. Euro Surveill. 2013;18(27):20519. DOI: 10.2807/1560-7917.ES2013.18.27.20519 PMID: 23870078
13. Italian National Institute of Statistics (ISTAT). Italian population census. ISTAT. Available from: http://demo.istat.it

14. Ministry of Health. Bollettino nazionale epidemiologico malattie infettive. Italian. Available from: http://www. salute.gov.it/portale/documentazione/p6_2_8_1_1. jsp?lingua=italiano\&id=3

15. Barco L, Ramon E, Cortini E, Longo A, Dalla Pozza MC, Lettini AA, et al. Molecular characterization of Salmonella enterica serovar 4,[5],12:i:- DT193 ASSuT strains from two outbreaks in Italy. Foodborne Pathog Dis. 2014;11(2):138-44. DOI: 10.1089/ fpd.2013.1626 PMID: 24328499

16. Italian National Statistician Institute (ISTAT). Censimento Popolazione. Italian. Available from: http://daticensimentopopolazione.istat.it/

17. Centre of Excellence for the Remote Sensing and Forecast of Severe Weather (CETEMPS). Available from: http://cetemps.aquila.infn.it/index. php?option=com_wrapper\&view=wrapper\&Itemid $=127$

18. R Core Team. R: A language and environment for statistical computing. Vienna, Austria: R Foundation for Statistical Computing.2013. Available from: http://www.R-project.org/

19. Lim YH, Hirose K, Izumiya H, Arakawa E, Takahashi H, Terajima J, et al. Multiplex polymerase chain reaction assay for selective detection of Salmonella enterica serovar typhimurium. Jpn J Infect Dis. 2003;56(4):151-5.PMID: 14583637

20. Alessiani A, Sacchini L, Pontieri E, Gavini J, Di Giannatale E. Molecular typing of Salmonella enterica subspecies enterica serovar Typhimurium isolated in Abruzzo region (Italy) from 2008 to 2010.Vet Ital. 2014;50(1):31-9.PMID: 24715591

21. Anderson ES, Ward LR, Saxe MJ, de Sa JD. Bacteriophagetyping designations of Salmonella typhimurium.J Hyg (Lond). 1977;78(2):297-300. DOI: 10.1017/So022172400056187 PMID: 321679

22. European Centre for Disease Prevention and Control (ECDC). Laboratory standard operating procedure for MLVA of Salmonella enterica serotype Typhimurium. Stockholm: ECDC; 2011.

23. Centre for Disease Prevention and Control (CDC). Standard Operating Procedure for PulseNet PFGE of Escherichia coli 0157:H7, Escherichia coli non-0157 (STEC), Salmonella serotypes, Shigella sonnei and Shigella flexneri. PNL05. Atlanta: CDC; April 2013.

24. International Nucleotide Sequence Database Collaboration, Leinonen R, Sugawara H, Shumway M. The sequence read archive.Nucleic Acids Res. 2011;39(Database issue):D19-21. DOI: 10.1093/nar/gkq1019 PMID: 21062823

25. Pettengill JB, Luo Y, Davis S, Chen Y, Gonzalez-Escalona N, Ottesen A, et al. An evaluation of alternative methods for constructing phylogenies from whole genome sequence data: a case study with Salmonella. PeerJ. 2014;2:e620. DOI: 10.7717/ peerj.620 PMID: 25332847

26. Tamura K, Stecher G, Peterson D, Filipski A, Kumar S. MEGA6: Molecular Evolutionary Genetics Analysis version 6.0. Mol Biol Evol. 2013;30(12):2725-9. DOI: 10.1093/molbev/mst197 PMID: 24132122

27. Liu C, Hofstra N, Franz E. Impacts of climate change on the microbial safety of pre-harvest leafy green vegetables as indicated by Escherichia coli 0157 and Salmonella spp. Int J Food Microbiol.2013;163(2-3):119-28. DOI: 10.1016/j. ijfoodmicro.2013.02.026 PMID: 23558195

28. Beuchat LR. Ecological factors influencing survival and growth of human pathogens on raw fruits and vegetables. Microbes Infect. 2002;4(4):413-23. DOI: 10.1016/S1286-4579(02)01555-1 PMID: 11932192

29. Himathongkham S, Bahari S, Riemann H, Cliver D. Survival of Escherichia coli $\mathrm{O}_{157}: \mathrm{H}_{7}$ and Salmonella typhimurium in cow manure and cow manure slurry. FEMS Microbiol Lett. 1999;178(2):251-7. DOI: 10.1111/j.1574-6968.1999.tbo8684.x PMID: 10499275

30. Horby PW, O’Brien SI, Adak GK, Graham C, Hawker II, Hunter $P$, et al. A national outbreak of multi-resistant Salmonella enterica serovar Typhimurium definitive phage type (DT) 104 associated with consumption of lettuce. Epidemiol Infect. 2003;130(2):169-78. DOI: 10.1017/S0950268802008063 PMID: 12729184

31. Golberg D, Kroupitski Y, Belausov E, Pinto R, Sela S. Salmonella Typhimurium internalization is variable in leafy vegetables and fresh herbs.Int J Food Microbiol. 2011;145(1):250-7. DOI: 10.1016/j.ijfoodmicro.2010.12.031 PMID: 21262550

32. The California Food Emergency Response Team. Investigation of the Taco John's Escherichia coli O157:H7 outbreak associated with iceberg lettuce. California: US Food and Drug Administration (FDA) and California Food Emergency Response Team; 2008. Available from: http://www.cdph. 
ca.gov/pubsforms/Documents/fdb\%2oeru\%2olceLet $\% 20$ TacoJohno22008.pdf

33. Centers for Disease Control and Prevention (CDC),. Outbreak of Salmonella serotype Saintpaul infections associated with multiple raw produce items--United States, 2008.MMWR Morb Mortal Wkly Rep. 2008;57(34):929-34.PMID: 18756191

34. Municipal Decree no. 70 of 12 June 2014. Available from: http://trasparenza.comune.laquila.gov.it/archivio28 provvedimenti_0_56240_725_1.html

35. Municipal Decree no. 74 of 7 th July 2014 . Available from: http://trasparenza.comune.laquila.gov.it/archivio28_ provvedimenti_0_59005_725_1.html

36. Municipal Decree no. 80 of 4 th August 2014. Available from: http://trasparenza.comune.laquila.gov.it/archivio28 provvedimenti_0_60959_725_1.html

\section{License and copyright}

This is an open-access article distributed under the terms of the Creative Commons Attribution (CC BY 4.0) Licence. You may share and adapt the material, but must give appropriate credit to the source, provide a link to the licence, and indicate if changes were made.

This article is copyright of the authors, 2016. 